\title{
The influence of external field on the lubricity of mineral oil for railway transport
}

\author{
Serhii Voronin ${ }^{1 *}$, Pavlo Konovalov ${ }^{1}$, Ivan Safoniuk ${ }^{1}$, and Oleksandr Kebko ${ }^{1}$ \\ ${ }^{1}$ Ukrainian State University of Railway Transport, Department of Construction, track and \\ handling machines, Feuerbach sq., 7, Kharkov, Ukraine, 61050
}

\begin{abstract}
The use of mineral oil is associated with its gradual operational degradation caused by its natural aging and contamination with various impurities. As the concentration of impurities increases, the number of active surface molecules which determine the operational properties of mineral oils decreases. A promising method of recovery of the operational properties of oils is the treatment with an electric field, which makes it possible to enhance the activity of surfactants in the tribo-contact area. This statement is proved through the improvement of the wettability of the bronze surface with mineral oils after their treatment with an electrostatic field. However, the method of electrical treatment is associated with the need to increase the requirements for the purity of liquids, especially to the presence of water, which requires creating an oil pre-treatment system. As an alternative, a method of electrical treatment with special field parameters is proposed enabling to accelerate the coalescence process. The major parameter that accelerates the coalescence process is the electric field oscillation frequency. The results of the study give grounds for choosing the optimal field parameters.
\end{abstract}

\section{Introduction}

The abrasion resistance of a friction pair depends on a number of performance characteristics of the lubricants with the universal decimal classification applied. One of the most important is their lubricity [1], which, in turn, is characterized by the ability of oils to form strong interfacial lubricating films on the surface of a friction pair [2, 3]. These properties of oils are estimated based on their ability to wet the friction surface. However, oil loses its wetting ability during operation as a result of the decrease in the concentration of polar molecules caused by the formation of molecular aggregates in the oil volume, the ingress of wear products, dust, and water. The existing cleaning methods, which include, among others, filtration, centrifugation, and sedimentation, are quite an energy- and timeconsuming. Therefore, the search for new effective methods to support the operating properties and purity of mineral oils remains an urgent task.

\subsection{Analysis of recent studies and publications}

\footnotetext{
* Corresponding author: voronin.sergey@ukr.net
} 
Mineral oil is a liquid isotropic dielectric, consisting of polar and nonpolar molecules, which arbitrarily move in volume. As they get into the external electric field, the oil is polarized $[4,5]$. As a result, the oil molecules in the volume become someway ordered, which consists in the fact that the dipole moments of the molecules, under the action of the external field, pass from random to organized orientation, close to equally directed, and pass from the micellar to the single state. An increase in the number of single molecules in the oil volume leads to the formation of a stronger molecular layer on the working surfaces.

\subsection{Statement of the objective and tasks of the study}

The objective of the study is to establish the possibility of applying EST to mineral oils used in the operation of construction and track-laying machines.

To achieve the set objective, the following tasks were solved:

- to determine the influence of the electrostatic field on the process of the metal surface wetting as an indirect indicator of the tribological properties of mineral oils;

- to propose a method of purification of the mineral oil before EST;

- to determine the dependence of the water droplet coalescence rate on the electric field parameters.

\section{The basic part of the study}

One of the tasks of our paper is an experimental study of the wetting properties of axial and industrial oils with respect to the bronze surface. The experiment was conducted with the use of a part made of bronze (GOST 613-79). The surface roughness of the used part is similar to the roughness of the friction surface of the axial bearing liner $R_{z}^{b}=7.5 \mu \mathrm{m}[6]$.

Before each experiment, the surface of the part was degreasared with $96 \%$ alcohol solution and treated mechanically with coal dust powder, according to recommendation [7]. The surface of the part was maintained in a horizontal state.

The studies were conducted with axial oil of grade "C", and with industrial oil I-30A. Each of the experiments compared the parameters of the wetting properties of the oil before and after its treatment with an electrostatic field of strength $E=0.5 \times 10^{6} \mathrm{~V} / \mathrm{m}$.

The dynamics of the wetting process was estimated using the wetting factor [8]

$$
k_{\mathrm{var}}=\frac{\left(S_{t}-S_{0}\right)}{S_{0}}
$$

where $S_{0}$ - the surface area occupied by an oil drop at the time of its application; $S_{t}$ - the surface area of the same drop 300 seconds after observation.

The experiments were carried out at an oil temperature of $(18-19){ }^{\circ} \mathrm{C}$. The diameter of the oil drops at the time of application onto the part surface was $6.5-8.5 \mathrm{~mm}$. The drop sizes during the experiments were recorded with a digital camera and then measured in the graphical program ACAD. Video shooting interval: the first two minutes - after 15 seconds, and the rest period - after 30 seconds.

Diagrams of the relative variation in wetting factor for axial and industrial oils with or without electrostatic treatment (EST) are shown in Fig. 1: 


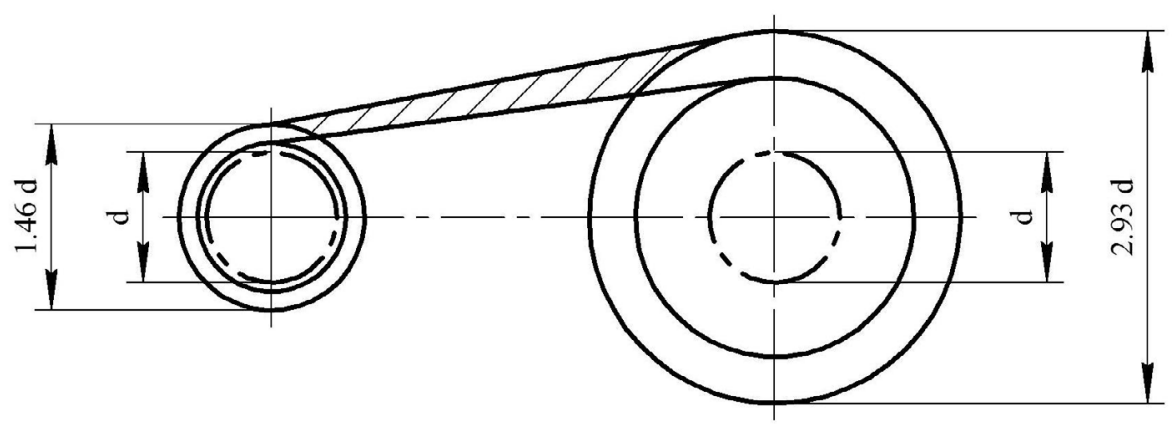

a

b

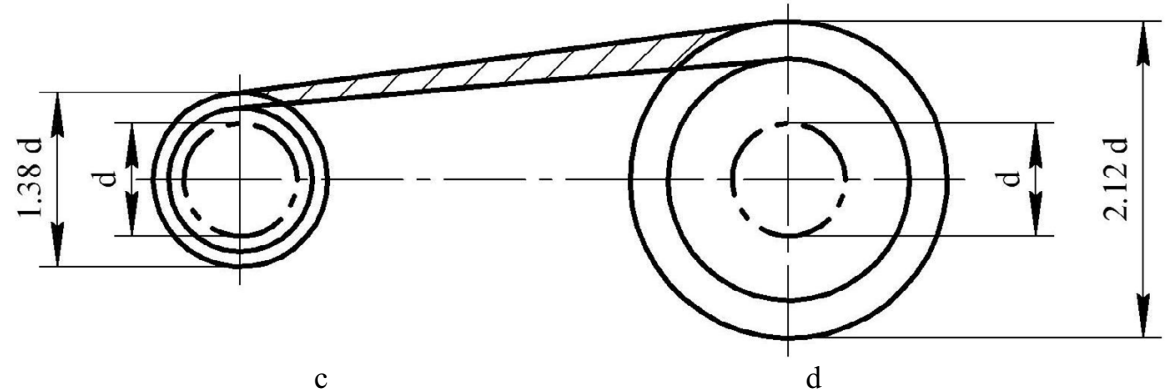

Fig. 1. The variation diagram of factor $k_{\text {var }}$ during 300 seconds for: a - axial oil without EST; b - the same with EST; c - industrial oil without EST; $d$ - the same with EST.

As can be seen from Fig. 1, EST of axial and industrial oils leads to activation of the process of the metal surface wetting. The wetting factor for axial oil after EST was 2.93 against 1.46 before treatment, and for the industrial oil -2.12 against 1.38 before EST, respectively.

Following on from the conducted studies, we can conclude about the effectiveness of the proposed method of improvement of the anti-wear properties of mineral oils, resulting in a slower process of losing their lubricating properties. Activation of the wetting process by EST is explained by an increase in the adsorption potential of axial oil, which is an indirect indicator of the improvement of its anti-wear properties.

On the other hand, the implementation of electrical treatment requires a high electric field strength between the electrodes and, at the same time, prevention of electrical breakdown of the oil $[5,9]$. It is known that during operation, the impurities of various nature enter the hydraulic oil, and significantly change its electrical conductivity, especially water. Such a problem makes it impossible to implement EST in many technical systems. Therefore, the implementation of EST in hydraulic drives of transport means should be accompanied by a preliminary removal of water, not settled in tanks, i.e., fine water.

The solution of this problem during the implementation of the on-board EST centers around of the study and creation of energy-saving (cold) methods for the removal of dispersed water. The main task is to remove droplets smaller than $5 \mu \mathrm{m}$. For such droplets, the action of the resistance force exceeds the action of gravitational forces, which makes their precipitation impossible. In this case, in order to accelerate the process of water precipitation in oil, it is necessary to create conditions for combining these droplets into larger ones. If a direct contact is necessary for combining the droplets, the main condition for their effective consolidation is as follows:

$$
A \geq D-d
$$


where $A$ - drop oscillation amplitude;

$D$ - distance between the random adjacent drops;

$d$-drop diameter.

The distance between the drops depends on the water concentration in the oil and the dispersion degree. The oscillation amplitude, in turn, depends on the geometric dimensions of the droplets, viscosity, density and parameters of the external electric field, namely, its intensity and frequency.

By changing the parameters of the external field we can affect the frequency and amplitude of the oscillations of microdroplets, however, in order to achieve maximum efficiency of the process of removing water from the oils, it is necessary to establish the rational values of the field parameters for each type of oil and the degree of initial dispersion of water.

We conducted a study of the process of water coalescence in a mineral oil environment. The study used an emulsion of industrial oil I-20 GOST 20799-88 (97\%) and industrial water $(3 \%)$. Since the coalescence of droplets is long and does not clearly time-restricted, we took the emulsion clarification time as the indicative time. The process of the emulsion clarification is shown in Fig. 2:

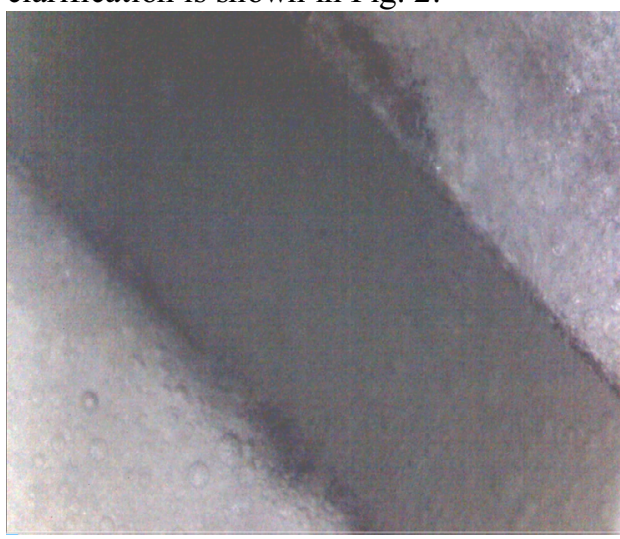

a

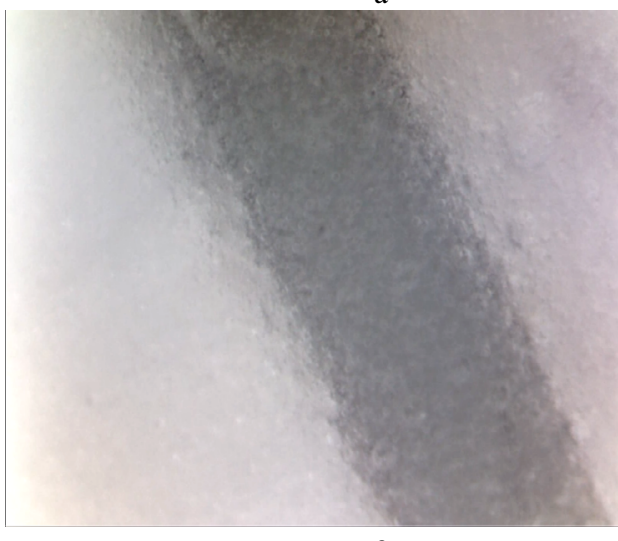

C

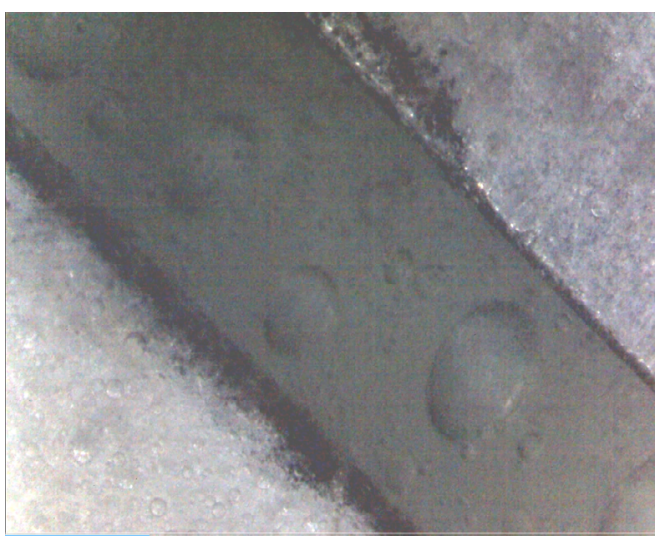

b

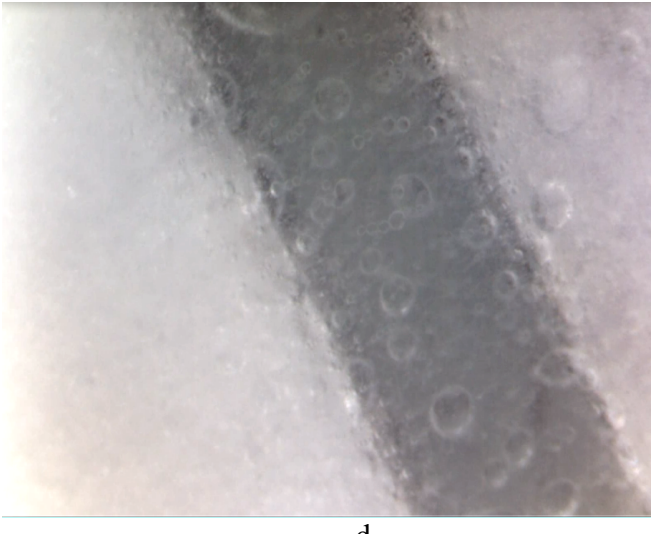

d

Fig. 2. The effect of electrical field on the emulsion: a - the initial state of the emulsion with noninsulated electrodes, $\mathrm{b}$ - clarified emulsion with non-insulated electrodes, $\mathrm{c}-$ the initial state of the emulsion with insulated electrodes, $\mathrm{d}$ - clarified emulsion with insulated electrodes.

The equipment for determining the emulsion clarification time consists of an optical microscope, a high voltage electrical signal generator, flat electrodes and a stopwatch. The method for determining the emulsion clarification time is as follows. The required 
oscillation frequency and voltage are set on the frequency generator. A drop of the prepared emulsion is placed on the electrodes of the laboratory unit. A de-oiled and dried $0.17 \mathrm{~mm}$ thick glass was used as a dielectric. The microscope eyepiece is focused on the middle of the drop. At the same time, the frequency generator and the stopwatch are turned on. The experiment ends with the clarification of the emulsion and the clarification time is recorded.

\section{Results and discussion}

The results of the studies show that the frequency of the external electric field has a significant effect on the coalescence of the oil. Based on the calculations, the time to field frequency curves was obtained, Fig. 3. The nonlinear relationship between the emulsion clarification time and frequency is established. At a frequency close to $300 \mathrm{~Hz}$, emulsion clarification begins after 50 seconds and lasts long (about 5 minutes), and at $3 \mathrm{MHz}$, the clarification begins after 7 seconds and lasts for 9 seconds.

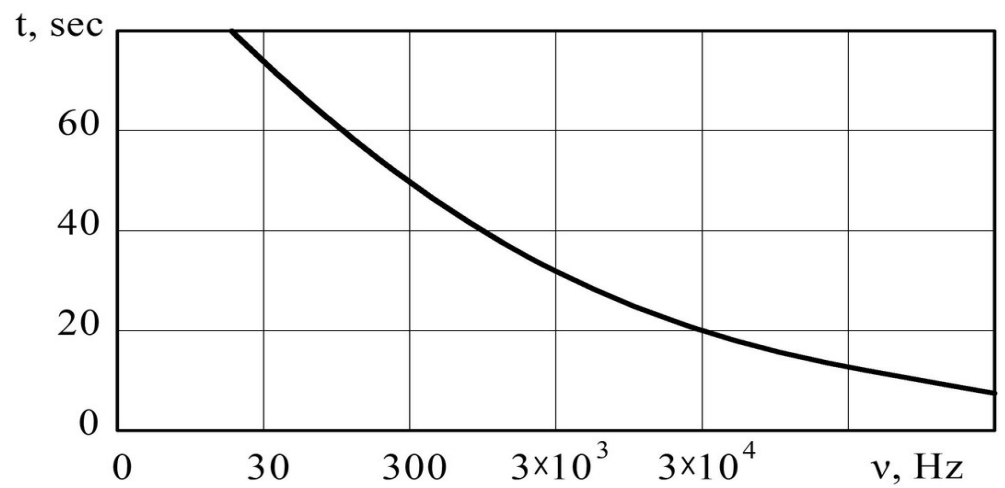

Fig. 3. The relationship between the emulsion clarification time and the oscillation frequency of the external electric field.

Such data allow determining the coalescence rate of water, as well as its variation depending on the frequency of the external field. For example, the relative coalescence rate at a frequency of $300 \mathrm{kHz}$ is $0.02 \mathrm{~s}^{-1}$ seconds, and at a frequency of $3 \mathrm{MHz}-0.143 \mathrm{~s}^{-1}$.

\section{Conclusion}

An essential reserve for the improvement of the anti-wear properties of axial and industrial oils, resulting in their slower loss of lubricity, is electrostatic treatment. The electrostatic treatment of oils intensifies the process of wetting of the metal surfaces. An increase in the intensity of the wetting process is characterized by an increase in the wetting factor for axial oil - by 2.93 times, and for industrial oil - by 2.12 times, respectively.

Activation of the wetting process is explained by the adsorption potential of mineral oil increasing under the influence of EST and the intensification of the process of formation of the interfacial lubricating layer on the friction surfaces, which is an indirect sign of improvement of its lubricating properties.

The possibility of cold removal of dispersed water through the coalescence of the droplets in an external electric field was proved. The results obtained can be used in the hydraulic systems of various transport means as a method for cleaning oil from water, and for preparing oil for EST. 


\section{References}

1. I.I. Karasik, F.V. Savvin, Trenie, iznashivanie i smazka. Terminy i opredeleniya (Izdatyelstvo standartov, Moscow, 1988)

2. S.V. Voronin, O.O. Skoryk, Ye.M. Korostelov, Eastern-European Journal of Enterprise Technologies. 4 (80). 11-17 (2016)

3. S.V. Voronin, O.O. Skoryk, V.O. Stefanov, D.V. Onopreychuk, Ye.M. Korostelov MATEC Web of Conferences. (to be published)

4. A.S. Akhmatov, Fizika. Elektrichestvo i stroenie atoma (Nauka, Moscow, 1974)

5. E.N. Lysikov, V.B. Kosolapov, S.V. Voronin, Nadmolekuliarnye struktury zhidkikh smazochnykh sred $i$ ikh vliianie na iznos tekhnicheskikh sistem (EDENA, Moscow, 2009)

6. V.A. Azarenko, Povyshenie nadezhnosti motorno-osevykh podshipnikov skolzheniia magistralnykh lokomotivov (Thesis by Ph.D. in Engineering, Moscow, 1984)

7. A.S. Akhmatov, Molekuliarnaia fizika granichnogo treniia (Publ. house fiz.-mat. lit., Moscow, 1963)

8. A.D. Zimon, Chto takoe adgeziia (Nauka, Moscow, 1983)

9. S.V. Voronin, A.V. Dunaev, Friction and wear. 1 (36) 41-49 (2015) 